\title{
RESEARCH PAPER \\ EFFECT OF AIR POLLUTION ON THE FOLIAR MORPHOLOGY OF SOME SPECIES IN THE FAMILY EUPHORBIACEAE IN SOUTHWESTERN NIGERIA
}

\author{
S. E. Ekpemerechi ${ }^{1}$, M. A. Lala ${ }^{2}$, L. A. Jimoda ${ }^{2}$, A. I. Odiwe ${ }^{1}$ and S. A. Saheed ${ }^{1^{*}}$ \\ ${ }^{1}$ Department of Botany, Faculty of Science, \\ Obafemi Awolowo University, Ile-Ife, BC 220005, Osun State, Nigeria. \\ ${ }^{2}$ Department of Chemical Engineering, Ladoke Akintola University of Technology, \\ Ogbomosho, Oyo State, Nigeria \\ *corresponding Author: saheed@oauife.edu.ng
}

\begin{abstract}
Morphological studies of the leaves of ten species in the family Euphorbiaceae collected from three different locations with different pollution levels in Southwestern Nigeria were carried out in order to establish the effect of air pollution on these species. The study was carried out in both dry and wet seasons. Climatic data and pollutants concentration levels of the study sites were determined. Leaf area of all the species was measured using an established nondestructive method while petiole length was determined using metric ruler. The result showed that most species showed significant reductions $(p<0.05)$ in the leaf area and petiole length across the three locations and this reduction is from rural to sub-urban to urban areas. Among all the species that showed reductions in leaf area, Alchornea cordifolia showed the highest response while Euphorbia hyssopifolia, E. hirta and Crotonlobatusdo not show clear reductions. Similar significant reductions were recorded for petiole length with the highest impact recorded in Manihot esculenta while species like E. hyssopifolia, E. hirta, C. lobatus and Flueggea virosa were not significantly reduced. This study showed that plants generally respond to air pollution with reduction in foliar morphology and the response is species specific.
\end{abstract}

Keywords: Pollution, leaf morphology, Euphorbiaceae, leaf area, petiole length

\section{INTRODUCTION}

The rapid economic growth, industrialization and urbanization with associated increases in energy demands results in continuous addition of toxic gases and other substances to the environment. Intensive industrial production is usually connected with the emission of various pollutants to the environment (Kalandadze, 2003; Uaboi-Egbenni et al., 2009). It has been observed that plants which grow in urban areas were affected greatly by varieties of pollutants such as oxides of nitrogen, sulphur dioxide, hydrocarbons, ozone, particulate matter, peroxyacyl nitrates (Jahan and Iqbal, 1992). These pollutants are known to have adverse effects on plants, especially those growing in urban or polluted areas with unfavourable environmental conditions (Qadir and Iqbal, 1991). 


\section{Saheed et al.}

Several workers (Ninoval et al., 1983; Bhatti and Iqbal, 1988; Anbazhagam et al., 1989; Jahan and Iqbal, 1992; Ali,1993; Chronopoulos et al., 1996; Preeti, 2000; Stevovic et al., 2010) have reported the effects of air pollution on the morphology (physical appearance) of different plant species. The effects of pollution on the morphology of plants are quite diverse depending on the constituents of the pollutants as well as the plant itself. Ninoval et al.(1983)in their study on Platanus acerifolia showed changes in leaf blade and petiole size of plants as a result of adaptation to air pollution. Reduction in the size of leaf blade of five tree species growing near heavy dust and $\mathrm{SO}_{2}$ polluted area was also observed by Sodnik et al.(1987). Stevovic et al. (2010) worked on Tansy plant and they showed that leaves from polluted site were significantly thinner than those from an unpolluted area. Significant reduction in length, breadth, area of leaves and length of petiole which were collected from plants growing in polluted area has also been reported (Iqbal, 1985, Jahan and Iqbal, 1992). This trend of reduction has also been recorded in a monocot (Oryza sativa) growing near a fertilizer plant with high concentrations of $\mathrm{SO}_{2}$ and $\mathrm{NO}_{2}$ (Anbazhagan et al., 1989).

Air pollution can directly affect plants via leaves or indirectly via soil acidification. When exposed to air-borne pollutants, most plants experienced physiological changes before exhibiting visible damage to leaves (Liu and Ding, 2008). Vegetation is an effective indicator of the overall impact of air pollution and the effect observed is a time-averaged result that is more reliable than the one obtained from direct determination of the pollutant in air over a short period. Large number of trees and shrubs have been identified and used as dust filters to check the rising urban dust pollution levels (Rai et al., 2010).

Most attention has been focused on the impact of industrial and urban emissions on human health (Fenger, 1999) and vegetation in urban areas. However, little is known about pollutant concentrations and exposure patterns in many suburban and rural areas as well as the associated impacts of these pollutants on the local vegetation especially in Nigeria. Therefore the present work aimed at investigating the effect of air pollution in urban, suburban and rural areas on the morphology of some plant species in the family Euphorbiaceae. The Euphorbiaceae family is a large one comprising trees, shrubs and herbs which are widely distributed in the tropics, sub-tropics and temperate regions (Olorode, 1984; Watson and Dallwitz, 1992). Their distribution indicates a high ecological plasticity and adaptability to different environmental conditions. The family includes many introduced species (Olorode, 1984) and it is of considerable economic importance since many of its species serves as source of food and drugs (Odugbemi, 2006),timber, while many are used as ornamentals (Illoh and Ndiribe, 2007).

\section{MATERIALS AND METHODS \\ Study area}

The study was conducted in three different locations in South western Nigeria (Fig. 1): along Tonkere village, after Road 8, Obafemi Awolowo University, Ile-Ife (rural area and the control site $-\mathrm{N} 07^{0} 32.243^{\prime}$; E004 $31.121^{\prime}$ ), IleIfe - Ibadan Toll Gate (sub-urban area - N $07^{0}$ 29.601'; E $004^{0} 29.483^{\prime}$ ) and Ibadan - Lagos Toll Gate (urban area - N $07^{0} 19.201^{\prime}$; E $003^{0}$ $\left.56.400^{\prime}\right)$. The sites were established approximately $50 \mathrm{~m}$ away from the roads.

\section{Environmental characteristics of the site}

The climatic variables measured at the study sites includes; mean relative humidity $(\mathrm{mm} /$ $\mathrm{m}^{2}$ ), mean temperature (Tmean, $\left.{ }^{0} \mathrm{C}\right)$, minimum temperature $\left(\mathrm{Tmin},{ }^{0} \mathrm{C}\right.$ ) and maximum temperature $\left(\operatorname{Tmax}^{0} \mathrm{C}\right)$. The geographical coordinates of the study sites were also determined using a high sensitivity GPS navigator, GARMIN (eTrex H), 2007 model. The stationary conditions (regarding the air pollutants present in the area or sites such as $\mathrm{SO}_{2}, \mathrm{NO}_{2}, \mathrm{NO}, \mathrm{CO}, \mathrm{PM}$, and $\mathrm{NH}_{3}$ ) were also measured with the range of TOXIRAE air sampler models (RAE Systems, 


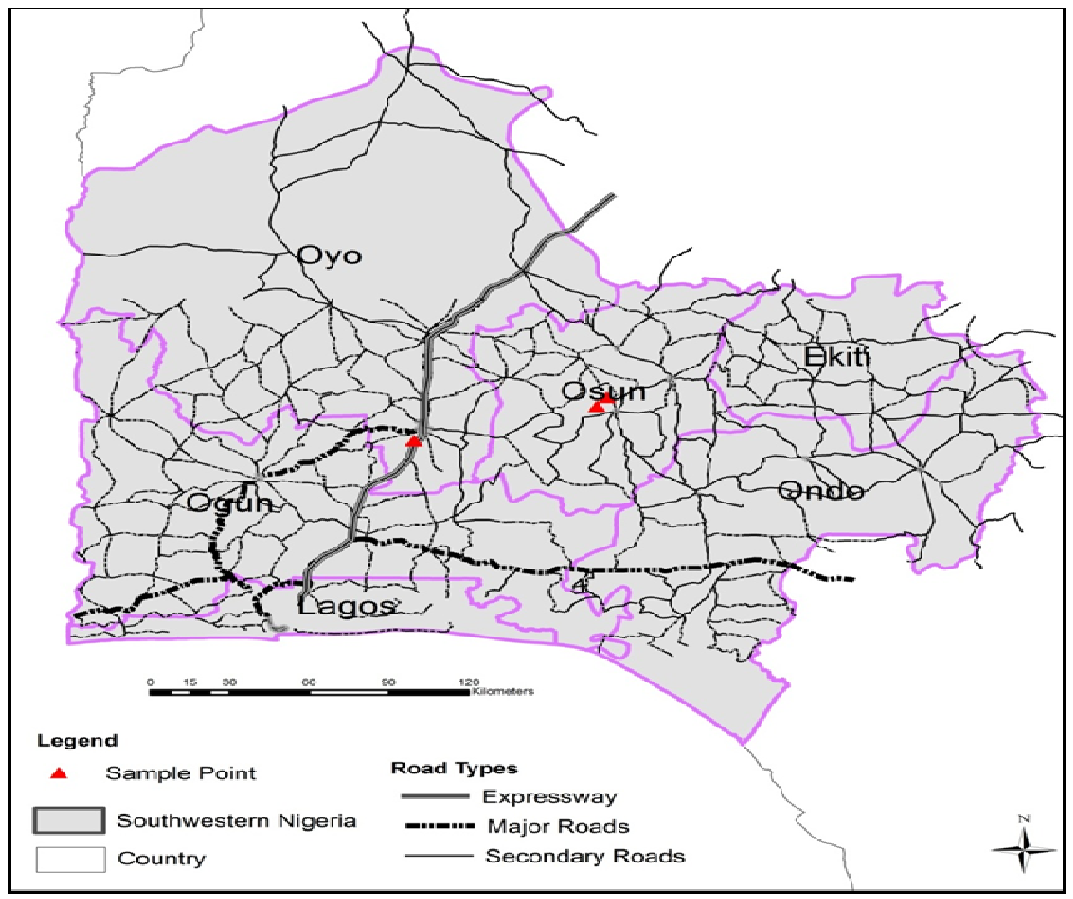

Fig. 1: Map of the study sites

San Jose CA, USA).

\section{Plant materials}

Reconnaissance survey into the study sites were carried out and it revealed that species of plants in Euphorbiaceae family are most frequently encountered; therefore the focus of this study is on some selected species within this family. Ten species were studied and they are: Alchornea laxiflora (Benth.)Pax and K. Hoffm., Alchornea cordifolia (Schum and Thonn.) Mull.Arg., Euphorbia heterophylla L., Euphorbia hyssopifolia L., E.hirta L., Croton lobatus L., Flueggea virosa (Willd) Voigt., Manihotesculenta Crantz.,Phyllanthus amarus (Schum and Thonn.) and Acalypha ornate Hochst. ex A. Rich. From each species, data were collected using the non-destructive method from leaves at the same leaf stage (the same level of insertion on the stem) from the three study sites, with maximum attention been given to plants that were closer to the traffic pathway thereby getting direct contact with auto-exhaust. The plant samples collections were done in wet and dry seasons. Mixing ratio which is defined as measure of atmospheric composition in microgram per cubic metre $\left(\mu \mathrm{g} / \mathrm{m}^{3}\right)$ was quantified for $\mathrm{SO}_{2}, \mathrm{NO}_{2}, \mathrm{NO}, \mathrm{CO}$ and $\mathrm{NH}_{3}$ in the air-shed of the study areas. The results obtained from this study were compared with National Ambient Air Quality Standard and finally, the effects of the air pollutants in the plant species were evaluated.

\section{DATA COLLECTION}

For leaf area study, the "millimeter graph paper method" described by Pandey and Singh (2011) was employed in measuring the leaf area of all the species investigated while petiole length measurement was made using a metric ruler. For each parameter, 20 measurements were made and the data were analyzed using a one 


\section{Saheed et al.}

way analysis of variance to test for significant differences in the observed effects of the pollutants on the parameters considered across the locations at the probability level of $\mathrm{p}<0.05$. The significant means were separated using a Post-hock test. SPSS statistical package Model 9.0 was used for the analysis.

\section{RESULTS}

The climatic variables measured in the three study sites (i.e. urban, sub-urban and rural) are presented in Table 1.

Generally, the temperature (maximum and minimum) were found to be higher in urban followed by sub-urban and the least in rural
(Table 1). Relative humidity was higher compared to other sites in both seasons. The air quality in terms of concentrations of the pollutants $\mathrm{SO}_{2}, \mathrm{NO}_{2}, \mathrm{NO}, \mathrm{CO}$, and $\mathrm{NH}_{3}$ in $\mu \mathrm{g} /$ $\mathrm{m}^{3}$ determined in the study sites are presented in Table 2. These values were compared with the National Ambient Air Quality Standards (NAAQS) to ascertain the degree of pollution in these locations. It is observed that the concentrations of these pollutants in urban and suburban areas appear to be generally higher than the NAAQS values but lower in the rural area in both seasons, except forSO $\mathrm{S}_{2}$,with similar concentrations in both seasons, the concentrations of other pollutants are higher in dry season than wet seasons.

Table 1:Climatic variables of the study sites in both dry and wet seasons

\begin{tabular}{|c|c|c|c|c|c|c|}
\hline \multirow[t]{2}{*}{$\begin{array}{l}\text { Environmental } \\
\text { characteristics }\end{array}$} & \multicolumn{3}{|c|}{$\begin{array}{c}\text { Dry Season } \\
\text { Location }\end{array}$} & \multicolumn{3}{|c|}{$\begin{array}{l}\text { Wet Season } \\
\text { Location }\end{array}$} \\
\hline & Urban & Sub-urban & Rural & Urban & Sub-urban & Rural \\
\hline Tmean $\left({ }^{0} \mathrm{C}\right)$ & 30.45 & 30.45 & 29.7 & 27.45 & 27.95 & 28.2 \\
\hline $\operatorname{Tmax}\left({ }^{0} \mathrm{C}\right)$ & 33.2 & 31.2 & 30.2 & 30.2 & 28.2 & 30.2 \\
\hline $\operatorname{Tmin}\left({ }^{0} \mathrm{C}\right)$ & 27.7 & 29.7 & 29.2 & 24.7 & 27.7 & 26.2 \\
\hline RH Mean (mb) & 55.1 & 56.88 & 62.13 & 58.1 & 58.88 & 66.13 \\
\hline
\end{tabular}

Table 2:Concentrations of pollutants measured in dry and wet seasons in the study sites

\begin{tabular}{|c|c|c|c|c|c|c|c|}
\hline \multirow[t]{2}{*}{ Pollutants } & \multicolumn{3}{|c|}{$\begin{array}{c}\text { Dry Season } \\
\text { Location } \\
\end{array}$} & \multicolumn{4}{|c|}{$\begin{array}{l}\text { Wet Season } \\
\text { Location } \\
\end{array}$} \\
\hline & Urban & Sub-urban & Rural & Urban & Sub-urban & Rural & NAAQS \\
\hline $\mathrm{SO}_{2}\left(\mu \mathrm{g} / \mathrm{m}^{3}\right)$ & 785.03 & 52.34 & 0.00 & 785.03 & 52.34 & 0.00 & 26.17 \\
\hline $\mathrm{NO}_{2}\left(\mu \mathrm{g} / \mathrm{m}^{3}\right)$ & $1,617.48$ & $1,410.59$ & 37.62 & $1,391.79$ & 169.27 & 18.81 & 75.23 \\
\hline $\mathrm{NO}\left(\mu \mathrm{g} / \mathrm{m}^{3}\right)$ & 932.22 & 527.44 & 0.00 & 686.90 & 306.65 & 0.00 & 49.06 \\
\hline $\mathrm{CO}\left(\mu \mathrm{g} / \mathrm{m}^{3}\right)$ & $14,882.80$ & $13,165.55$ & 0.00 & $13,737.97$ & $12,581.69$ & 0.00 & $11,448.31$ \\
\hline $\mathrm{NH}_{3}\left(\mu \mathrm{g} / \mathrm{m}^{3}\right)$ & 695.08 & 347.54 & 0.01 & 660.32 & 312.78 & 0.00 & 194.62 \\
\hline
\end{tabular}


Effect of air pollution on species in the family Euphorbiaceae...

In both dry and wet seasons, the leaf area and petiole length of the plant species measured were found to vary across the locations and they are species specific. The detailed results are as presented in Tables 3 and 4 respectively.

\section{DISCUSSIONS}

The three study sites have similar general climate but different microclimate and contamination degree. The absence of or presence of very low concentrations of primary pollutants in the rural area (Table2) showed that the environment and the plant species growing there are relatively free from pollutant contaminations when compared to the those growing in suburban and urban areas. Since the study sitesshared similar general climate but different microclimate and contamination degree, it might be that the most likely factor in this study is the pollution levels. The high concentrations of pollutants found in sub-urban and urban areas are due to high rate of automobiles, industrial and other anthropogenic activities going on in the areas. This is supported byAgrawal (1985)who reported in India that motor vehicles account for $60-70 \%$ of the pollution found in urban environment followed by industries 20$30 \%$. It is also in agreement with the studies by Kalandadze, (2003) and Uaboi-Egbenni et al., (2009)where intensive industrial production has been connected with the emission of various pollutants to the environment.

Plants in urban and sub-urban areas are continuously exposed to different pollutants (carbon monoxide, oxides of nitrogen, sulphur dioxide and particulate matter etc) which are released into the environment as a result of incomplete combustion in the automobile engines. Though this study revealed that all the plants species studied showed no easily recognizable morphological injuries, however, some hidden injury or physiological disturbances might have occurred which caused reduction in the morphological characters investigated. This is in line with the findings of Dohmen et al. (1990) who reported that when exposed to airborne pollutants, most plants experienced phys-

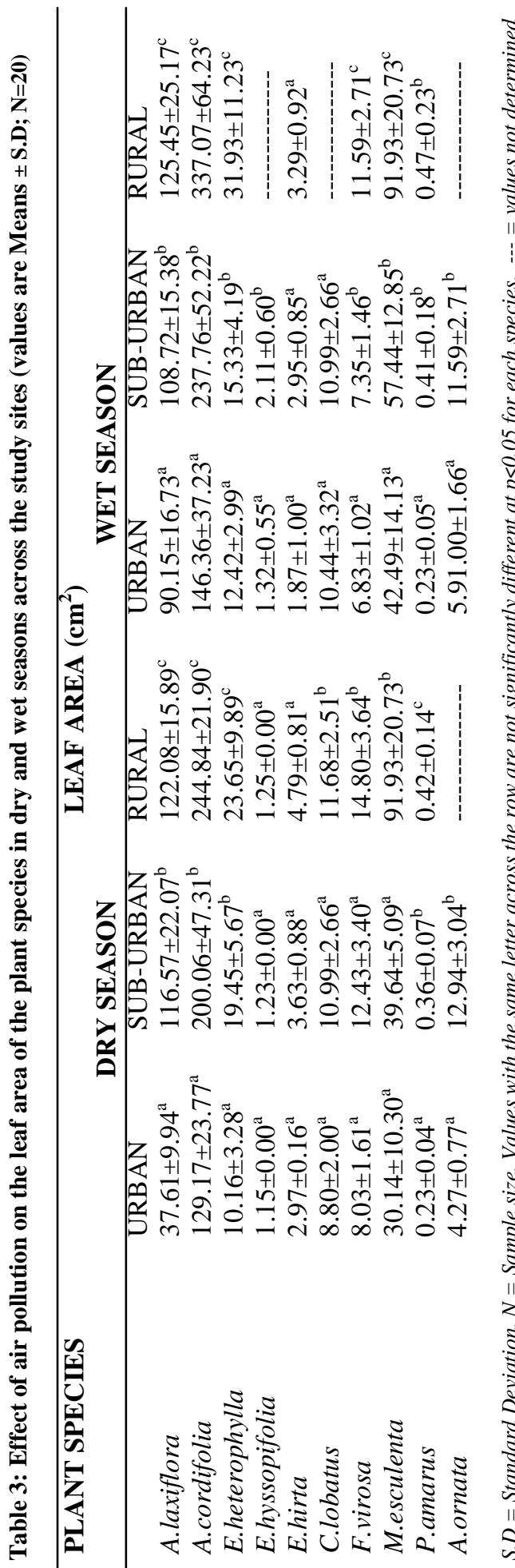


iological changes before exhibiting visible damage to leaves.

Our results shows that there is significant reductions $(p<0.05)$ in the mean leaf area of most of the studied species growing in sub-urban and urban areas when compared to those growing in rural area (Tables 3 and 4) and this is what is observed in both dry and wet seasons. This observation is consistent with earlier work by Ninoval et al.(1983), where similar changes in leaf blade and petiole size of Platanus acerifolia growing in polluted air were observed. Also a reduction in the size of leaf blade of five tree species growing near heavy dust and $\mathrm{SO}_{2}$ polluted area was also observed by Sodnik et al. (1987). The report by Stevovic et al.(2010) on Tansy plant equally demonstrates that leaves from plants growing in polluted site were significantly thinner and reduced than those from an unpolluted area was in support of the current study. Other studies have demonstrated reductions in leaf area of plants growing in the vicinity of heavy pollutions in many plants species (Bhatti and Iqbal, 1988; Gupta and Ghouse, 1988; Shafiq et al., 2009). The observed reduction in leaf area has been suggested to be due to reduction in leaf production rate and senescence which may be as a result of many factors including reduced photosynthetic rate (Tiwari et al., 2006; Seyyednejad et al., 2011).

Generally, the result of this study showed that in all the species investigated, A.laxiflora, $A$. cordifolia, M. esculenta, F. virosa and A. ornata were most frequently affected by pollutants when compared to other species (Tables 3 and 4), they appears to be most susceptible to these pollutants since reductions in the leaf area and petiole length for these plants showed significance reductions across the three locations and seasons. Among all these species, A. cordifolia showed the highest impact with the biggest reduction in leaf area, despite the fact that it has the largest leaf area while M. esculenta showed the highest impact with respect to petiole length. In contrast, E. heterophylla, E. hyssopifolia, E. hirta, C. lobatus and P. amarus 
appear to be more resistant to the pollutants recorded in this study due to the fact that the reductions experienced by these species across the three locations were most times not significantly different from each other. Our results are in agreement with previous studies such Heath, (1980), Agrawal and Deepak, (2003); Honour et al. (2009) among others where they have shown that the response of plants to air pollution has been reported to vary with different plant species.

In terms of the seasonal effects however, the effect of pollution on the plants studied was significantly higher during the dry season when compared to the wet season. This is probably due to higher pollutants concentrations and the drier conditions of the atmosphere in the dry season with less dilution effects. The concentration of the air pollutants except $\mathrm{NH}_{3}$ exceeded the NAAQS values in the dry season in urban and sub-urban areas while it is within the limit in the rural area. In the wet season, the concentrations are all above the NAAQS in urban and sub-urban when compared with the rural area which is within the limit. This observation has been previously reported by Jahan and Iqbal (1992) as well as Naveed et al. (2010) that pollutants concentrations in the air vary with seasons.

\section{CONCLUSION}

It is clear from this study that the foliar morphology of selected plant species in Euphorbiaceae family are affected by air pollution and that these effects are species specific. The differences observed in the morphological features occurred in all the foliar parameters investigated across the three locations and between the two seasons. This shows that the effect do not occur by chance, rather it is due to the varying levels of pollutants concentrations in the three locations. The result from this study will help to bridge the gap on the amount of information available on the impact of pollution on foliar morphological features especially in $\mathrm{Ni}$ geria. It will also help to better our understanding of the impact of pollution on foliar morpho- logy as well as serving as a basis of future studies in this area. There might be the need to carry out further investigation to assess if the observed morphological changes will be reflected on the functional leaf anatomical characters of these plant species.

\section{REFERENCES}

Agrawal, M. and Deepak, S. S. (2003). Physiological and biochemical responses of two cultivars of wheat to elevated levels of $\mathrm{CO}_{2}$ and $\mathrm{SO}_{2}$, singly and in combination Environmental Pollution 121: 189-197

Agrawal, M. (1985). Plant factor as indicator of $\mathrm{SO}_{2}$ and $\mathrm{O}_{3}$ pollutants. Proc. International symposium on Biological Monitoring of the state Environment (Bio-indicator), Indian National Science Academy, New Delhi, 225-231.

Ali, E. A. (1993). Damage to plants due to industrial pollution and their use as bioindicators in Egypt. Environmental Pollution 81: $251-255$.

Anbazhagan, M., Krishnamurthy R. and Bhagawat K. A. (1989). The performance of three cultivars of rice grown near to and distance from a fertilizer plant. Environmental pollution 58: 125-137.

Bhatti, G. H. and Iqbal, M. Z. (1988). Investigations into the effect of automobile exhausts on the phenology, periodicity and productivity of some roadside trees. Acta Socintatis Botanicorum Pololonia 57: 395399.

Chronopoulus, J., Chronopoulus-Sereli A. and Papafotiou, M. (1996). The capability of adaptation of woody ornamental plants to the urban environment of Athens. Gartenbauwissenschaft 61: 197-200.

Dohmen, G. P., Loppers, A. and Langebartels, C. (1990). Biochemical Response of Norway Spruce (Picea Albies (L) Karst) 
Toward 14- Month Exposure to Ozone and Acid mist, effect on amino acid, Glutathione and Polyamine Titers. Environmental Pollution 64: 375-383.

Fenger, J. (1999).Urban air quality. Atmospheric Environment 33: 4877-4900.

Gupta, M. C. and Ghouse, A. K. M. (1988). Effects of coal smoke pollutants from different sources in the growth, chlorophyll content, stem anatomy and cuticular trait of Euphorbia hirta L. Environmental Pollution 47: 221-230.

Heath, R. L.(1980).Initial events in injury to plants by air pollution. Annual Review of Plant Physiology 31: 395-431.

Honour, S. L., Bell, J. N., Ashenden, T.W., Cape, J. N. and Power, S. A. (2009). Responses of herbaceous plants to urban air pollution: Effects on growth, phenology and leaf surface characteristics. Environmental Pollution 157: 1279-1286.

Illoh, H. C. and Ndiribe, C. C., (2007). Plant Album-A Pictoral collection of plants in Nigeria. SOS Publishers, Agege-Lagos, Nigeria.

Iqbal, M. Z. (1985).Cuticular and anatomical studies of white clover leaves from clean and air-polluted areas. Pollution Research 4: 59-61.

Jahan, S. and Iqbal, M. Z. (1992). Morphological and Anatomical Studies on Leaves of Different Plants Affected by Motor Vehicle Exhaust. Journal of Islamic Academy of Sciences 5: 21-23.

Kalandadze, B. (2003). Influence of the ore mining and processing enterprise on soil types in adjoining areas. Agronomy Research 1: 131-137.

Liu, Y. J. and Ding, H. (2008).Variation in air pollution Tolerance Index of Plants Near a steel Factory: Implication for Landscape-plant Species Selection for Industrial Areas. WSEAS Transactions on Environmental Development 4: 24-32.

Naveed, N. H., Batool, A. I., Rehman, F. U. and Hameed U. (2010). Leaves of roadside plants as bio indicator of traffic related lead pollution during different seasons in Sargodha, Pakistan. African Journal of Environmental Science and Technology, 4 (11):770-774.

Ninoval, D. J., Dushkova, P. I. and Kovacheva, G.V. (1983). Anatomical, Morphological studies of Platanusacerifolia at various degrees of air pollution. Ekologiya (Sofia) 6: 35-47.

Odugbemi, T. O. (2006). Outline and pictures of medicinal plants from Nigeria, University of Lagos Press, Lagos, Nigeria.

Olorode, O. (1984). Taxonomy of West African Flowering Plant. Longman Group Ltd. London and New York

Pandey, S. K. and Singh, H. (2011). A simple cost-effective method for leaf area estimation. Journal of Botany, doi:10.1155/2011/658240.

Preeti, A. (2000).Study of leaf area damage of urban and rural environment in Agra. Acta Ecologica 22: 96-100.

Qadir, S. A. and Iqbal, M. Z. (1991). Growth of some plants raised from polluted and unpolluted seeds. International Journal of Environmental Studies 39: 95-99.

Rai, A., Kulshreshtha K., Strivastava, P. K. and Mohanty C. S., (2010). Leaf Surface Structure Alterations due to Particulate Pollution in Some Common Plants. Environmentalist 30: 18-23. 
Seyyednejad, S. M., Niknejad, M. and Koochak, H. (2011). A review of some different effects of air pollution on plants. Research Journal of Environmental Sciences, 5(4): 302-309.

Shafiq, M., Iqbal, M. Z., Anthar, M. and Qayyum, M. (2009). Effect of auto exhaust emission on the phenology of Cassia siamea and Peltophorum pterocarpum growing in different areas of Karachi. African Journal of Biotechnology, 8 (11): 24692475.

Sodnik, H., Skrezyna, J. J. and Staszkiewicz, J. (1987). The effect of industrial pollution in Walbrzych (Poland) on the size and shape of leaves of selected species of trees. Rocznik Sekcji Dendrologicznej PolskiegoTowarzystwa Botanicznego, 36: 17-34.

Stevovic, S., Vesna, S. M. and Dusica C. (2010). Environmental impact on morpho- logical and anatomical structure of Tansy. African Journal of Biotechnology, 9 (16): 2413-2421.

Tiwari, S., Agrawal, M. and Marshall, F. M. (2006). Evaluation of ambient air pollution impact on carrot plants at a sub urban site using open top chambers. Environmental Monitoring and Assessment, 119: 15-30.

Uaboi-Egbenni, P. O., Adejuyitan, O. E., Sobande, A. O. and Akinyemi O. (2009). Effect of industrial effluent on the growth and anatomical structures of Abelmoschusesculentus (okra). African Journal of Biotechnology, 8: 3251-3260.

Watson, L. and Dallwitz, M. J. (1992). The families of flowering plants: descriptions, illustrations, identification, and information retrieval. Version: 19th December 2012. http://delta-intkey.com'(Accessed $20^{\text {th }}$ December, 2012). 